University of Wollongong

Research Online

Faculty of Engineering and Information

Faculty of Engineering and Information

Sciences - Papers: Part A

Sciences

$1-1-2013$

\title{
Sizing optimization of trapezoidal corrugated roof sheeting, supporting solar panels, under wind loading
}

P Sharafi

University of Wollongong, psharafi@uow.edu.au

Lip H. Teh

University of Wollongong, Iteh@uow.edu.au

Muhammad N. S Hadi

University of Wollongong, mhadi@uow.edu.au

Follow this and additional works at: https://ro.uow.edu.au/eispapers

Part of the Engineering Commons, and the Science and Technology Studies Commons

Research Online is the open access institutional repository for the University of Wollongong. For further information contact the UOW Library: research-pubs@uow.edu.au 


\title{
Sizing optimization of trapezoidal corrugated roof sheeting, supporting solar panels, under wind loading
}

\begin{abstract}
The dimensions of trapezoidal roof sheeting supporting solar panels are optimized so that a minimum amount of steel is required for a specific range of wind loads. Sheets of different grades and different thicknesses along with different ranges of wind speeds are considered. In order to simulate the behavior of the corrugated sheets analysis is carried out for two limit states: strength and serviceability. For both limit states, the objective is to minimize the weight per unit area of the panels. First, optimum crosssection is obtained to meet the strength conditions. Then the deflection is controlled for serviceability. The optimum dimensions for each steel grade and loading condition are determined. The optimization problem is formulated as a multi-objective problem that aims to minimize the section's weight and maximize the section elastic modulus under the wind loading condition. A graph theory based approach is presented for the sizing optimization, employing an applied graph theory approach for the multiobjective all pairs shortest path problem. The proposed methodology addresses the sizing optimization problem to determine the geometry of the thin-walled cold-formed steel cross-sections that satisfy the design topological constraints.
\end{abstract}

\section{Keywords}

under, panels, solar, supporting, optimization, sheeting, sizing, roof, corrugated, trapezoidal, loading, wind

\section{Disciplines}

Engineering | Science and Technology Studies

\section{Publication Details}

Sharafi, P., Teh, L. H. \& Hadi, M. N. S. (2013). Sizing optimization of trapezoidal corrugated roof sheeting, supporting solar panels, under wind loading. In F. N. Catbas, S. Pakzad, V. Racic, A. Pavic \& P. Reynolds (Eds.), Topics in Dynamics of Civil Structures - Proceedings of the 31st IMAC, A Conference on Structural Dynamics (pp. 535-542). New York, United States: Springer. 


\title{
Sizing Optimization of Trapezoidal Corrugated Roof Sheeting, Supporting Solar Panels, under Wind Loading
}

\author{
P. Sharafi ${ }^{* 1}$, Lip. H. Teh ${ }^{2}$, Muhammad N. S. Hadi ${ }^{3}$ \\ School of Civil, Mining and Environmental Engineering, University of Wollongong, Northfields \\ Avenue, Wollongong, NSW 2522, Australia
}

\begin{abstract}
The dimensions of trapezoidal roof sheeting supporting solar panels are optimized so that a minimum amount of steel is required for a specific range of wind loads. Sheets of different grades and different thicknesses along with different ranges of wind speeds are considered. In order to simulate the behavior of the corrugated sheets analysis is carried out for two limit states: strength and serviceability. For both limit states, the objective is to minimize the weight per unit area of the panels. First, optimum cross-section is obtained to meet the strength conditions. Then the deflection is controlled for serviceability. The optimum dimensions for each steel grade and loading condition are determined. The optimization problem is formulated as a multi-objective problem that aims to minimize the section's weight and maximize the section elastic modulus under the wind loading condition. A graph theory based approach is presented for the sizing optimization, employing an applied graph theory approach for the multi-objective all pairs shortest path problem. The proposed methodology addresses the sizing optimization problem to determine the geometry of the thin-walled cold-formed steel cross-sections that satisfy the design topological constraints.
\end{abstract}

Keywords: sizing optimization, roof sheeting, wind load, graph theory, multi-objective optimization

\section{Introduction}

Cold-formed steel profiles are manufactured by bending thin sheets of steel to desired shapes allowing efficient and light profiles to be used where conventional hot-rolled profiles prove to be uneconomic. One of the main advantages of cold-formed steel profiles is the great flexibility of cross-sectional shapes to the manufacturing process allowing almost any desired cross-sections to be achieved. The cross-sectional shape is the key element in enhancing the strength of cold-formed steel profiles as it controls the three fundamental buckling modes: local, distortional (for open profiles) and global. Cold-formed profiled metal sheeting and decking are well-established construction products and manufacturers make strenuous efforts to keep these products competitive in terms of the carrying capacity for a given weight of material.

\footnotetext{
${ }^{1}$ Research Associate/PhD candidate, School of Civil, Mining and Envir. Eng., Univ. of Wollongong, Wollongong, NSW, Australia.*(Corresponding author). Email address: ps170@uow.edu.au

${ }^{3}$ Senior Lecturer, School of Civil, Mining and Envir. Eng., Univ. of Wollongong, Wollongong, NSW, Australia

${ }^{2}$ Assoc. Professor, School of Civil, Mining and Envir. Eng., Univ. of Wollongong, Wollongong, NSW, Australia.
} 
Most sheeting and decking profiles can sustain considerable redistribution of bending moment so that the attainment of the calculated moment of resistance at an internal support is not immediately followed by failure. After yielding and/or buckling at the support, 'plastic hinge' action occurs, possibly accompanied by a reduction in the moment of resistance, until failure takes place when the full moment of resistance is attained within the span. Because the midspan moment of resistance is often greater than the (reduced) moment of resistance at a support, the increase in the load carried as a result of this moment redistribution can be considerable [1].

Since the steel sheets can be formed to almost any shape to suit structural and constructional requirements, finding optimal shapes for cold-formed steel sections is a problem of strong interest, where optimization of sections is aimed at achieving efficient use of the steel material either by maximizing the desirable properties of the section for a given mass and/or by minimizing the mass for a given application. Optimization of thin-walled steel sections is mostly performed to obtain improvements in strength, serviceability, and vibration characteristics.

Because of the many types of sheeting available and the diverse functional requirements and loading conditions that apply, design and optimization of sheeting is generally based on experimental investigation. Therefore, there are a limited number of published papers in the literature on the theory based optimization of cold-formed sheeting steel structures. Lee at al. [2] optimized the profile of corrugated claddings by minimizing the bending stresses due to the bending moment for a set of dimensional constraints on the coverage, the contour length, and the height of the profile. Lu and Mäkeläinen [3] applied genetic algorithms for optimization of dimensions of cold-formed steel trapezoidal sheeting to obtain the minimum weight subjected to the given constraints.

The structural performance of a cold-formed steel section depends not only on the characteristics of their components, but also on their relative locations and connectivity (topology). Graph theory based modes are powerful means to represent structural systems so that their geometry and topology can be understood clearly. A graph can be used to represent almost any physical situation involving discrete objects and the relationships among them. Graph theory methods are readily formulated for a wide range of structural problems as a result of interaction with other fields of mathematics, and can be applied with only minimal changes to a wide range of combinatorial optimization problems [4-8].

During the last few decades, combinatorial optimization and graph theory methods have experienced fast developments since many problems in combinatorial optimization arise directly from everyday practice in engineering and management. One of the advantages of graph theory based approaches is that an optimization problem of a continuous form can be transformed to one of a discrete form, where the variables belonging to the space $R^{\mathrm{n}}$ are finite dimensional. In fact, graph theory approaches can be considered as a link between discrete spaces and continuous ones. Employing the graph theory, the sizing optimization problem changes to a combinatorial optimization problem of discrete space.

This paper presents a graph theory approach for sizing optimization of cold-formed steel sections. The main concern is not to investigate thoroughly the advantages of the graph theory approach over alternative approaches. The primary objective is to illustrate a general method to find the dimensions of minimum mass and/or maximum strength for cold-formed steel sections that satisfy the constraints. The sizing optimization of sheeting is treated as a multi-objective shortest path problem. Then, the method is employed to optimize the dimensions of trapezoidal panels carrying solar modules on, in order to minimize the weight of sheeting as well as resisting a specific range of wind loading and/or hail stones impact loads under some constraints.

\section{Multi- objective Shortest Path Problems}

A multi-objective optimization problem $f=\left(f_{1}, f_{2}, \ldots, f_{Q}\right)$ is a problem of finding a vector of decision variables that satisfies the constraints and optimizes the vector function $f$ whose elements $f_{l}$ through $f_{Q}$ represent the $Q$ number of objective functions, which are usually in conflict with each other. In the present graph theory approach, the objective of the shortest path problem is to find a shape for the thin-walled steel section that has the minimum mass possible and the maximum strength possible [9]. 
A graph $G(N, E)$ consists of a set of nodes $N$ and a set of edges $E$, with a relation of incidence that associates each edge with a pair of nodes as its ends. As shown in Fig. 1, a path $P$ of graph $G$ is a finite sequence whose terms are alternately nodes and edges, in which no edge or node appears more than once. A cycle $C$ is a path for which the starting node and the ending node are the same; i.e. a cycle is a closed path. The length of a path (or cycle) $L$ is taken as the number of its edges.

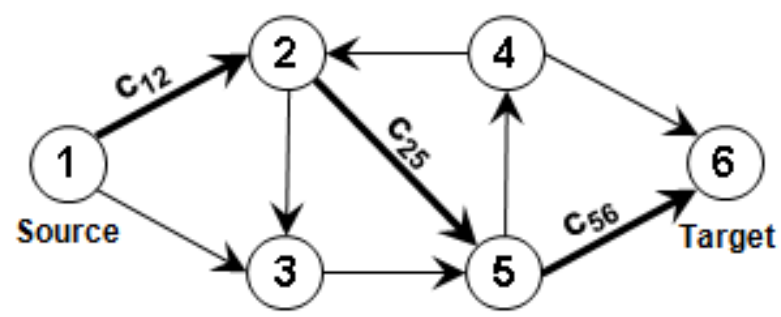

$$
\begin{aligned}
& \text { a) A path and the coresponding cost: } \\
& P=\left[n_{1}, e_{12}, n_{2}, e_{25}, n_{5}, e_{56}, n_{6}\right] \\
& \text { cost: } L(P)=c_{12}+c_{25}+C_{56}
\end{aligned}
$$

Fig. 1: A path and the corresponding cost on a directed graph

In the graph theory, the shortest path problem is the problem of finding a path from a specified node called the source, to a second specified node, called the destination (or target), such that the sum of the weights (or lengths) of its constituent edges is minimized. It is relevant to a wide variety of real world applications, such as in telephone routing, material distribution, salesperson routing, investment strategies and personnel scheduling. The shortest path problem is an NP-hard combinatorial optimization problem, which means that it is strongly believed that they cannot be solved to optimality within polynomially bounded computation time. To practically solve large instances, one often has to use heuristics that returns near-optimal solutions in a relatively short time $[10,11]$.

Consider a weighted undirected graph $G(N, E)$. Let $n=|N|$ and $m=|E|$. Each edge $e_{i j} \in E$ is assigned a cost (or length) of $c_{i j}$. If $c_{i j}$ has multiple criteria, the problem is called a multi-objective shortest path problem. In this case the edge $e_{i j}$ has associated values $c_{i j}^{k}$, in which $k \in\{1,2, \ldots, r\}$ for each criterion $k=1,2, \ldots, r$. Obviously, for undirected graphs $c_{i j}^{k}=c_{j i}^{k}$. The adjacency set $A(i)$ for node $i$ is the set of all edges incident from $i$, that is $A(i)=\{(i, j) \mid(i, j) \in E\}$. The integer programming formulation for the multi-objective shortest path problem from Node $s$ to Node $t$ can be given as follows [12]:

$$
\begin{array}{r}
\min f=\left(\sum_{i, j \in V} c_{i j}^{1} e_{i j}, \sum_{i, j \in V} c_{i j}^{2} e_{i j}, \ldots, \sum_{i, j \in V} c_{i j}^{r} e_{i j}\right) \\
\forall e_{i j} \in E: \quad e_{i j}=\left\{\begin{array}{lr}
1 \quad \text { if Edge } e_{i j} \text { is chosen } \\
0 \quad \text { if Edge } e_{i j} \text { is not chosen }
\end{array}\right. \\
\forall i \in N-\{s, t\}: \quad \sum_{j} e_{i j}-\sum_{k} e_{k i}=0 \\
\forall i, j \in N: \quad \sum_{i} e_{s i}-\sum_{j} e_{j s}=1 \\
\forall i, j \in N: \quad \sum_{i} e_{i t}-\sum_{j} e_{t j}=1
\end{array}
$$


Equation (1) represents the objective and Eq. (2) defines the binary variable $e_{i j}$. Equations (3) through (5) are the constraints.

Equation (3), as an ordinary flow conservation constraint, states that for all nodes except for the source and target points, the edges leaving them are equal to the edges entering them. Equations (4) and (5) state that the difference between the number of edges leaving the source and target points and the number of edges entering them, respectively, is one. In other words, the edges are not on a cycle.

\section{Discrete Sizing Optimization}

To minimize the mass is to minimize the cross-section area $A$. Since the thickness of the cross-section is uniform and invariable, the mass minimization of the section reduces to the length minimization of the section. The dimensional constraints on the elements (edges) of a cross-section are defined considering the effective width (or depth) for the elements [13]. Some fabrication, construction or manufacturing constraints may also be applied to the cross-sectional dimensions.

Although it is believed that a sizing optimization problem with discrete design variables is more difficult to solve than a similar problem with continuous design variables, structural optimization methods employing the zero-one based decision making scheme are capable of dealing with the sizing optimization problem using discrete variables $[14,15]$. In a sizing optimization problem, there are a finite number of variables along with some benchmarks defining the boundary of the cross-section. Figure 2 shows the benchmarks and the complete variables of some standard sections. Depending on the problem at hand, each variable defined in Fig. 2 may or may not be used as a design variable.

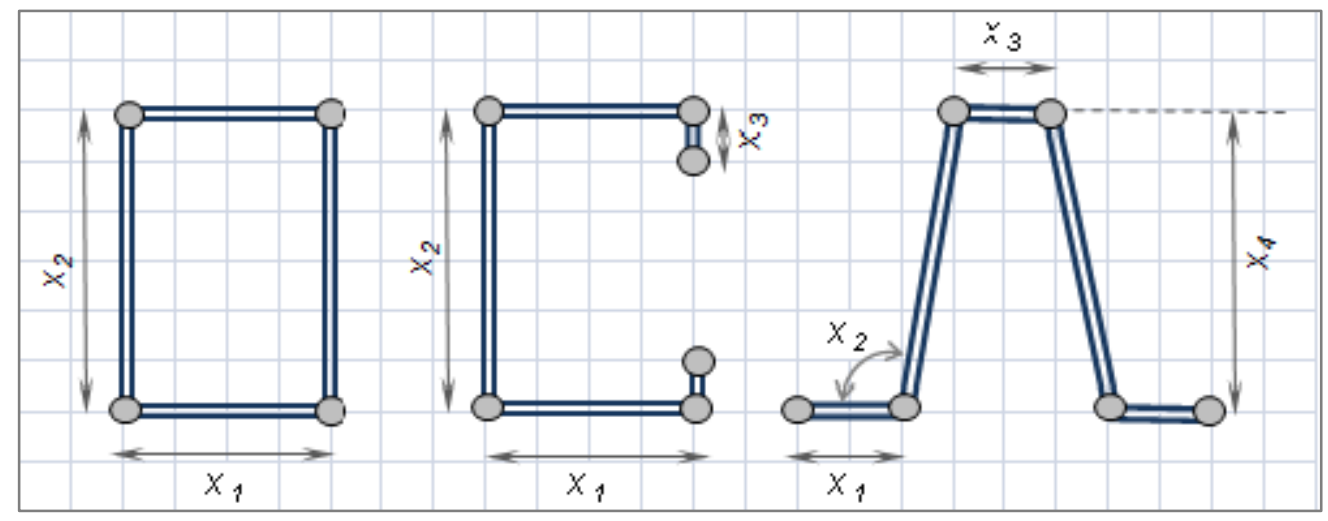

Fig. 2: Benchmarks and variables for sections of constant thickness

Consider a cross-section of sheeting, lying in the $x-y$ plane under a general set of actions, resulting in compression, flexural, torsional and shear action effects. The problem is to find the dimensions resulting in the optimum mass and section strength. "Section strength" is a generic term that corresponds to the imposed action effects.

In order to define a graph model for dimension optimization, the first step is to discretize the search space for each variable. To that end, each variable $x_{i}$ is bounded between $\left[\operatorname{Min}\left(x_{i}\right), \operatorname{Max}\left(x_{i}\right)\right]$ with interval (accuracy) of $\varepsilon$, then each variable $x_{i}$ rests in the set of $\left[\operatorname{Min}\left(x_{i}\right), \operatorname{Min}\left(x_{i}\right)+\varepsilon, \ldots, \operatorname{Max}\left(x_{i}\right)-\varepsilon, \operatorname{Max}\left(x_{i}\right)\right]$, which contains $m_{i}=\left(\left(\operatorname{Max}\left(x_{i}\right)-\operatorname{Min}\left(x_{i}\right)\right) / 2\right)+1$ possible conditions. If the number of variables is $v$, the graph corresponding to the sizing optimization problem consists of $n=v+1$ nodes and $m=v \sum m_{i}$ edges as shown in Fig. 3 [16]. Any path through the graph represents a 
section with known dimensions. The objective functions are formulated in the same manner as those shown in the preceding section on shape optimization.

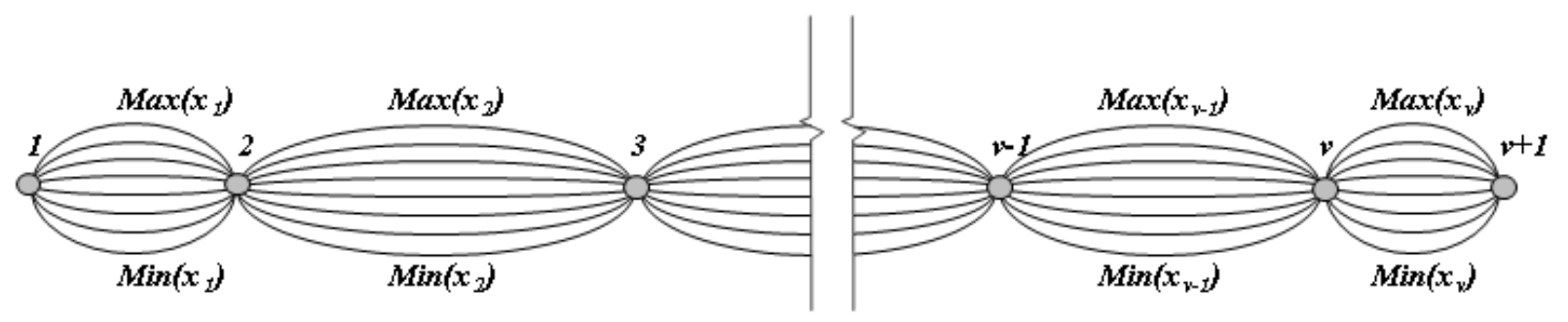

Fig. 3: A Graph for dimension optimization

Now, the problem of sizing optimization is a multi-objective single-pair shortest path problem whose aim is to find the shortest path between a specific pair of nodes. The optimization problem can generally be formulated as follows:

$$
\begin{gathered}
\min f=\left(W, 1 / S_{G}\right) \\
\text { s.t. }\left\{\begin{array}{l}
\text { geometrical constraints } \\
\text { constraints on strength }
\end{array}\right.
\end{gathered}
$$

where $W$ is the section's mass, and $S_{G}$ is the section strength that is a generic term and, depending on the instance may mean the strength with respect to axial compression, flexural, torsional or shear action effects. In practice, the parameters that represent the section strength are mostly the second moments of area, the torsion constant or the cross-sectional area. The geometrical constraints in sizing optimizations of cold-formed steel sections, on the other hand, may be due to the design standards, the manufacturing and the installation requirements. For example, AS/NZ4600 [13] imposes dimensional limitations, such as maximum width to thickness ratio of the plate element.

Since in practice it is almost impossible to optimize the dimensions of sections with respect to various limit states, the section strength is dealt with as a single objective in the rest of this paper, which renders the problem represented by Eq. (6) a bi-objective optimization problem. However, it should be noted that the underlying approach is valid and applicable for multiple limit states. In the present study, the optimum solution is the one that provides the best compromise between two potentially conflicting objectives of mass minimization and strength maximization. One approach for finding the solution is to find the Pareto-optimal set, or at least a good approximation of it.

\section{Sizing Optimization of Roof Sheeting}

The abovementioned methodology is employed for cross-sectional optimization of trapezoidal corrugated sheeting, supporting solar panels, under wind loading. The optimization is carried out on trapezoidal corrugated sheets for roofing "Lysaght Trimdek", produced by BlueScope Steel [17], of three different grades and eight different thicknesses as shown in Table 1. Lysaght Trimdek, shown in Fig. 3, is a suitable roof profile for installing solar panels on. According to Eqs. (1) and (6), there are two potentially conflicting objectives, mass minimization and flexural strength maximization. 


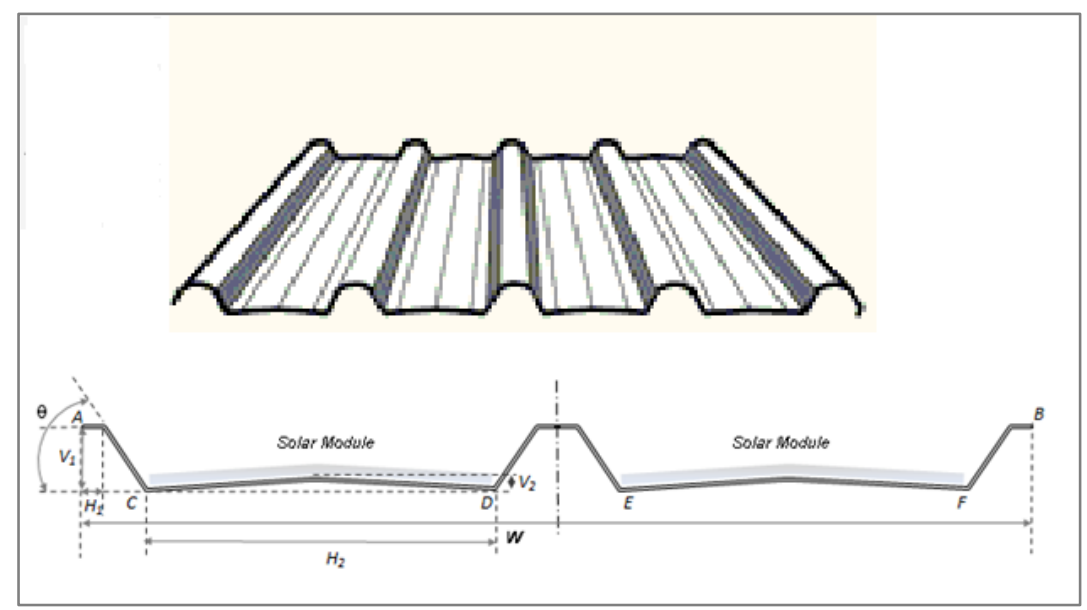

Fig. 4: The Initial Selected Profile (Lysaght Trimdek)

Three ranges of wind speeds are considered from the Australian Standards for wind loads for housing (AS 40552006) [18], as shown in Table 2. Geometrical constraints are either manufacturing constraints or the ones that are required by Australian/New Zealand standards for cold-formed steel structures (AS/NZS 4600:2005) [13] as shown in Table 3 and Table 4 . The aim is to optimize the dimensions of the trapezoidal panel in order to minimize its mass (first objective) and maximize its flexural stiffness (second objective).

Table 1. Mechanical Properties of Steel Sheets

\begin{tabular}{|c|c|c|c|c|c|}
\hline $\begin{array}{l}\text { Steel } \\
\text { Type }\end{array}$ & $\begin{array}{l}\text { Thickness } \\
\text { (BMT mm) }\end{array}$ & Yield strength (MPa) & Yield strain & Ultimate strength (MPa) & $\begin{array}{l}\text { Ultimate } \\
\text { strain }\end{array}$ \\
\hline \multirow{3}{*}{ ST1 } & 0.55 & 300 & 0.0015 & 340 & 0.18 \\
\hline & 0.60 & 300 & 0.0015 & 340 & 0.18 \\
\hline & 0.80 & 300 & 0.0015 & 340 & 0.18 \\
\hline & & & & & \\
\hline \multirow{7}{*}{ ST2 } & 0.35 & 550 & 0.00275 & 550 & 0.01 \\
\hline & 0.42 & 550 & 0.00275 & 550 & 0.01 \\
\hline & 0.48 & 550 & 0.00275 & 550 & 0.01 \\
\hline & 0.60 & 550 & 0.00275 & 550 & 0.02 \\
\hline & 0.80 & 550 & 0.00275 & 550 & 0.02 \\
\hline & 0.90 & 550 & 0.00275 & 550 & 0.02 \\
\hline & 1.00 & 550 & 0.00275 & 550 & 0.02 \\
\hline \multirow{8}{*}{ ST3 } & 0.35 & 750 & 0.00375 & 750 & 0.01 \\
\hline & 0.42 & 750 & 0.00375 & 750 & 0.01 \\
\hline & 0.48 & 750 & 0.00375 & 750 & 0.01 \\
\hline & 0.55 & 750 & 0.00375 & 750 & 0.01 \\
\hline & 0.60 & 750 & 0.00375 & 750 & 0.02 \\
\hline & 0.80 & 750 & 0.00375 & 750 & 0.02 \\
\hline & 0.90 & 750 & 0.00375 & 750 & 0.02 \\
\hline & 1.00 & 750 & 0.00375 & 750 & 0.02 \\
\hline
\end{tabular}

As shown in Figure 4, four geometric design variables are defined for the problem: rib height (V1), rib width (H1), rib slope $(\theta)$ and flat pan midpoint height (V2). Due to the solar panels fixed width, being installed on flat pan (around $400 \mathrm{~mm}$ ), the width of flat pan is considered constant. That is, for all models $\mathrm{H} 2$ is assumed to be $400 \mathrm{~mm}$. Therefore, using the single-pair shortest path problem, the construction graph for this problem consists of five nodes. 
Table 2. Wind Loading Pressure

\begin{tabular}{|c|c|c|c|c|}
\hline \multirow{2}{*}{ Wind Class } & \multicolumn{2}{|c|}{ Design Guest Wind Speed (m/s) } & \multicolumn{2}{c|}{ Pressure for Roof (kPa) } \\
\cline { 2 - 5 } & Serviceability Limit State & Ultimate Limit State & Ultimate Strength & Serviceability \\
\hline N3 & 32 & 50 & -3.00 & -1.33 \\
\hline N4 & 39 & 61 & -4.47 & -2.14 \\
\hline N5 & 47 & 74 & -6.57 & -3.29 \\
\hline
\end{tabular}

For solving the shortest path problem arisen from the sizing optimization there are many algorithms and methods, [19]. In this paper an Ant Colony algorithm is used to deal with the problem. The principles of the algorithm can be found in $[16,20,21]$. The shortest path is the one with the minimum weight. Therefore in the problem of biobjective shortest path problem arisen from the sizing optimization of the sheeting, the optimum solution for each case is the first one in the Pareto optimal set.

Table 3. Manufacturing Geometric Constraints

\begin{tabular}{|c|c|c|c|c|c|c|c|}
\hline \multicolumn{2}{|c|}{ Flat pan width (H2) } & \multicolumn{2}{c|}{ Rib Height (V1) } & \multicolumn{2}{c|}{ Support Spacing (L) } & \multicolumn{2}{c|}{ Flat Pan Height (V2) } \\
\hline $\operatorname{Min}(\mathrm{mm})$ & $\operatorname{Max}(\mathrm{mm})$ & $\operatorname{Min}(\mathrm{mm})$ & $\operatorname{Max}(\mathrm{mm})$ & $\operatorname{Min}(\mathrm{mm})$ & $\operatorname{Max}(\mathrm{mm})$ & $\operatorname{Min}(\mathrm{mm})$ & $\operatorname{Max}(\mathrm{mm})$ \\
\hline 350 & 700 & 16 & 50 & 600 & 1200 & 0 & 20 \\
\hline
\end{tabular}

The sensitivity analysis of the model, in relation to the involved parameters, is demonstrated in Figure 5, which shows how sensitive each parameter is to the variations of design variables. As can be seen in Figure 5, the trapezoidal panels' mass, maximum deflection and maximum normal strain are most sensitive to the thickness. In the ranges defined for the variables, the panels' mass is least sensitive to the flat pan height. However, deflection, maximum normal strain and maximum equivalent (Von -Mises) strain are highly sensitive to the flat pan height. The maximum equivalent elastic strain is most sensitive to the angle of ribs. Almost all stated parameters are not highly sensitive to the ribs height in the range defined for them (between 16 to $50 \mathrm{~mm}$ ). The optimum points, stated in Table 4, verify the above mentioned results.

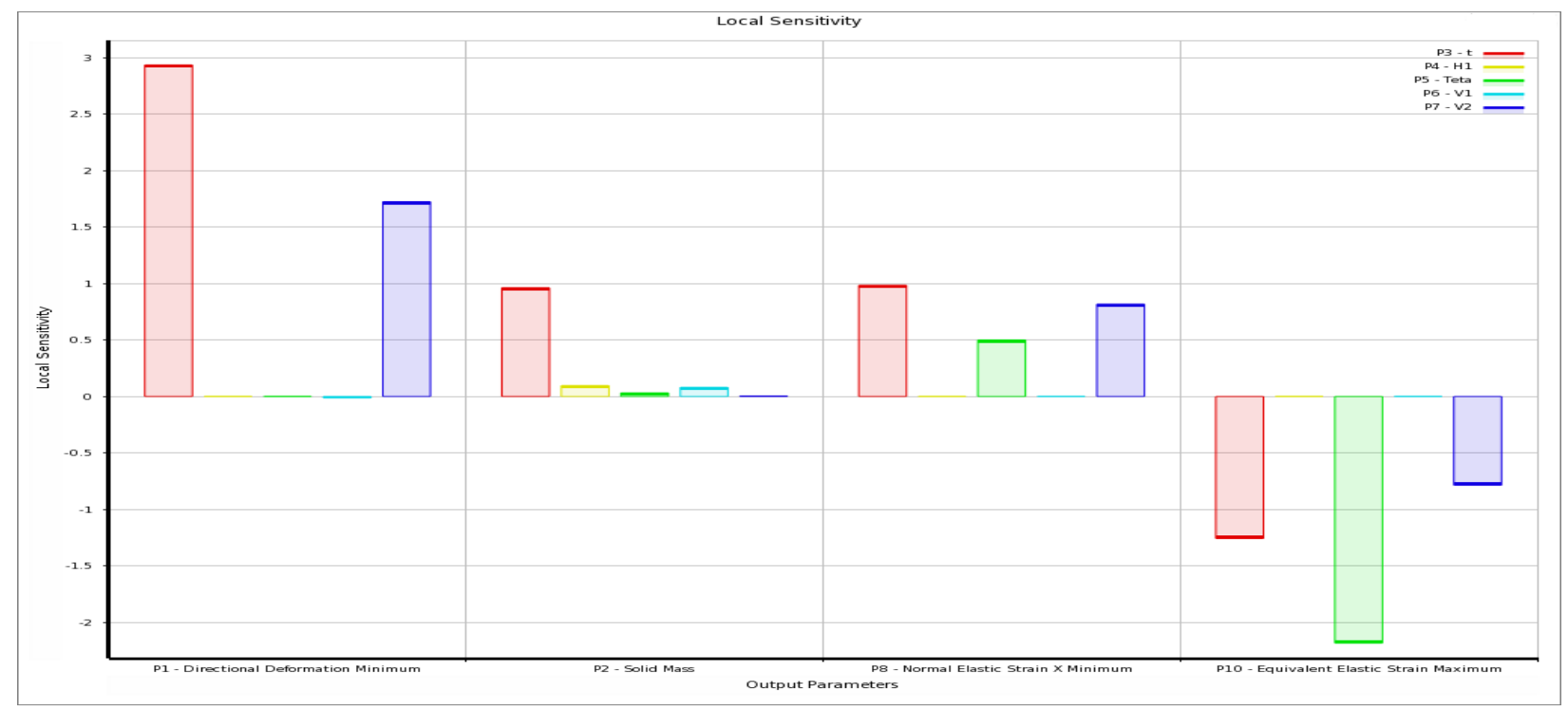

Fig. 5: Design sensitivity in relation to the involved parameters 
Results suggest that, for the steel Grades 2 and 3 (ST2 and ST3) a minimum sheeting thickness of $0.48 \mathrm{~mm}$ is required for wind class N4 and N5, due to serviceability constraints. For the steel grades 1 (ST1), all sheeting thickness seem to be suitable for wind class N3, N4 and N5.

Table4. Optimum Design Points for Wind Loading

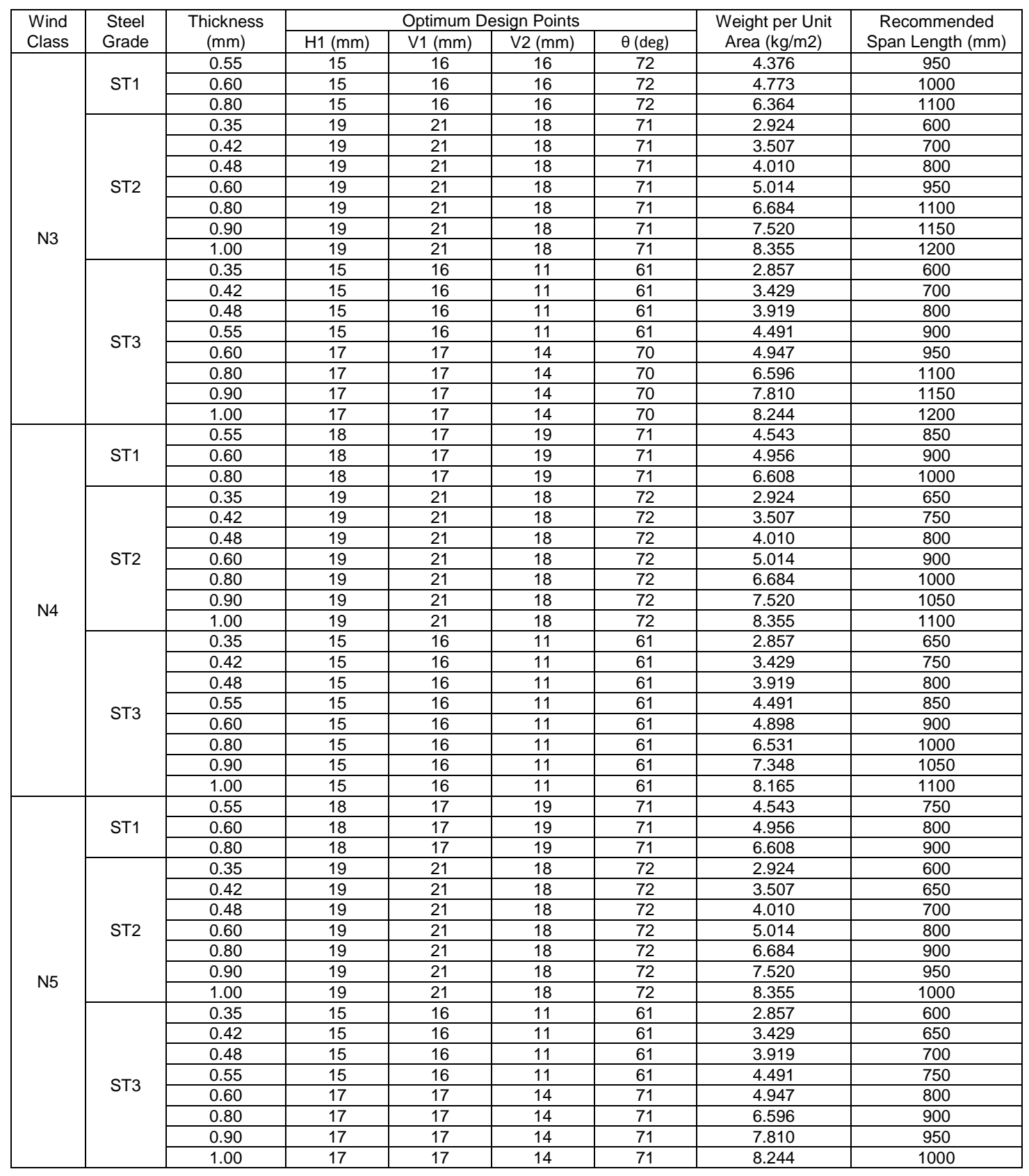




\section{Concluding Remarks}

A new method for sizing optimization of cold-formed steel sections is presented using a graph theory approach. The optimization problem is formulated as a multi-objective problem that aims to minimize the section's mass and maximize the section flexural strength. The sizing optimization of sheeting is treated as a multi-objective shortest path problem.

Lysaght Trimdek sheets of different grades and different thicknesses along with different ranges of wind speeds are considered. In order to simulate the behavior of the corrugated sheets analysis is carried out for limit states design. The objective is to minimize the weight per unit area of the panels along with the maximum flexural strength. The presented method can be applied to a wide range of similar multi-objective sizing optimization problems.

\section{Acknowledgment}

Funding of this research project was provided by the Bluescope Steel Metallurgy Centre at the University of Wollongong, sponsored by the Faculty of Engineering and Bluescope Steel Limited. Any opinions expressed are those of the authors alone.

\section{References}

1. Davies, J.M. and Jiang, C., Design procedures for profiled metal sheeting and decking. Thin-Walled Structures, 1997. 27(1): p. 43-53.

2. Lee, C.-L., Mioduchowski, A., and Faulkner, M.G., Optimization of Corrugated Claddings. Journal of Structural Engineering, 1995. 121(8): p. 1190-1196.

3. Lu, W. and Mäkeläinen, P., Fuzzy optimization of cold-formed steel sheeting using genetic algorithms. Journal of Constructional Steel Research, 2006. 62(12): p. 1276-1281.

4. Kaveh, A., Structural mechanics: graph and matrix methods. 2004: Research Studies Press.

5. Kaveh, A., Optimal structural analysis. 2006: John Wiley.

6. Kaveh, A. and Sharafi, P., Ant colony optimization for finding medians of weighted graphs. Engineering Computations, 2008a. 25(2): p. 102-120.

7. Kaveh, A. and Sharafi, P., Optimal priority functions for profile reduction using ant colony optimization. Finite Elements in Analysis and Design, 2008b. 44(3): p. 131-138.

8. Kaveh, A. and Sharafi, P., Nodal ordering for bandwidth reduction using ant system algorithm. Engineering Computations, 2009. 26(3): p. 313-323.

9. $\quad$ Sharafi, P., Teh, L.H., and Hadi, M.N.S., Shape and Sizing Optimization of Cold Formed Steel Sections: A Unified Graph Theory Approach. Thin-Walled Structures (Submitted), 2012.

10. Korte, B. and Vygen, J., Combinatorial Optimization: Theory and Algorithms. 2012: Springer.

11. Lawler, E.L., Combinatorial Optimization: Networks and Matroids. 2001: Dover Publications.

12. Reinhardt, L.B. and Pisinger, D., Multi-objective and multi-constrained non-additive shortest path problems. Computers \&amp; Operations Research, 2011. 38(3): p. 605-616. 
13. As/Nz4600, cold formed steel structures 2005, Standards Australia Limited/ Standards New Zealand: Sydney.

14. Steven, G.P., Li, Q., and Xie, Y.M., Multicriteria optimization that minimizes maximum stress and maximizes stiffness. Computers \&amp; Structures, 2002. 80(27-30): p. 2433-2448.

15. Burns, S.A., Recent advances in optimal structural design. 2002: American Society of Civil Engineers.Structural Engineering Institute. Technical Committee on Optimal Structural Design.

16. Sharafi, P., Hadi, M.N.S., and Teh, L.H., Heuristic Approach for Optimum Cost and Layout Design of 3D Reinforced Concrete Frames. Journal of Structural Engineering, 2012. 138(7): p. 853-863.

17. LYSAGHT TRIMDEK®, in BlueScope_Steel, http://www.lysaght.com/product/lysaght-trimdek: Australia.

18. As4055, Wind Loads for housing 2006, Standards Australia Limited/ Standards New Zealand: Sydney.

19. Gross, J.L. and Yellen, J., Handbook of Graph Theory. 2003: Taylor \& Francis.

20. Sharafi, P., Hadi, M.N.S., and Teh, L.H., Optimum Column Layout Design of Reinforced Concrete Frames Under Wind Loading Topics on the Dynamics of Civil Structures, Volume 1, J.M. Caicedo, et al., Editors. 2012, Springer US. p. 327-340.

21. Sharafi, P., Hadi, M.N.S., and Teh, L.H., Optimum Spans' Lengths of Multi-span Reinforced Concrete Beams Under Dynamic Loading Topics on the Dynamics of Civil Structures, Volume 1, J.M. Caicedo, et al., Editors. 2012, Springer US. p. 353-361. 